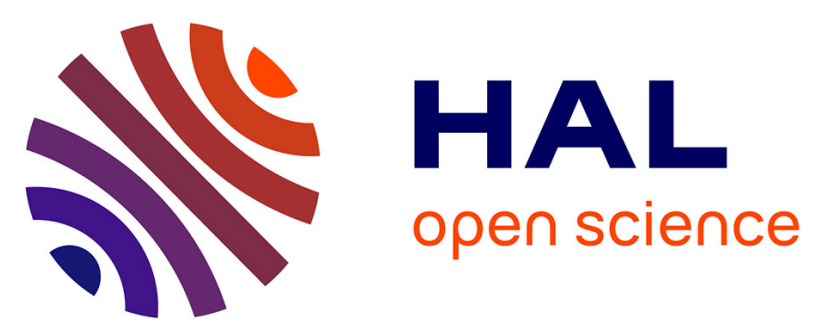

\title{
Rice and Einkorn wheat husks reinforced poly(lactic acid) (PLA) biocomposites: Effects of alkaline and silane surface treatments of husks
}

Thi Phuong Thao Tran, Jean-Charles Benezet, Anne Bergeret

\section{- To cite this version:}

Thi Phuong Thao Tran, Jean-Charles Benezet, Anne Bergeret. Rice and Einkorn wheat husks reinforced poly(lactic acid) (PLA) biocomposites: Effects of alkaline and silane surface treatments of husks. Industrial Crops and Products, 2014, 58, pp.111-124. 10.1016/j.indcrop.2014.04.012 . hal02914351

\section{HAL Id: hal-02914351 \\ https://hal.science/hal-02914351}

Submitted on 25 May 2021

HAL is a multi-disciplinary open access archive for the deposit and dissemination of scientific research documents, whether they are published or not. The documents may come from teaching and research institutions in France or abroad, or from public or private research centers.
L'archive ouverte pluridisciplinaire HAL, est destinée au dépôt et à la diffusion de documents scientifiques de niveau recherche, publiés ou non, émanant des établissements d'enseignement et de recherche français ou étrangers, des laboratoires publics ou privés. 


\title{
Rice and Einkorn wheat husks reinforced poly(lactic acid) (PLA) biocomposites: Effects of alkaline and silane surface treatments of husks
}

\author{
Thi Phuong Thao Tran ${ }^{\mathrm{a}, \mathrm{b}, *}$, Jean-Charles Bénézet ${ }^{\mathrm{a}}$, Anne Bergeret ${ }^{\mathrm{a}}$ \\ a Centre des Matériaux des Mines d'Alès (C2MA), 6 avenue de Clavières, 30319 Alès, France \\ b School of Textile, Leather and Fashion, Hanoi University of Science and Technology, 1 Dai Co Viet, Hanoi, Viet Nam
}

\section{A B S T R A C T}

This paper investigated specific surface treatments, aimed to improve the adhesion between PLA and rice and Einkorn wheat husks. In the first part, husks were treated by alkaline solutions at three concentrations (2, 5 and 10\%) at room temperature for different times between 6 and $48 \mathrm{~h}$. Results revealed that the alkaline treatment dissolved a fraction of waxes, lignin and hemicellulose, so that the polarity of their surface was increased and therefore alkaline treated husks were more sensitive to moisture. Moreover the alkaline treatments have more influence on wheat than on rice husks, as shown by chemical composition determination, FTIR measurements and ESEM observations. In the second part, husks were treated by two kinds of organosilanes ( $\gamma$-aminopropyltriethoxysilane(APS) and $\gamma$-glycidoxypropyltrimethoxysilane GPS)). These silane treatments were applied either alone or on previously alkaline treated husks ( $\mathrm{NaOH}$ $5 \%$ for $24 \mathrm{~h}$ ). The results showed that silane treatments reduced the moisture sensitivity and raise the energy surface of the husks. In the last part, treated husks were incorporated into polylactic acid (PLA) to produce biocomposites. Biocomposites reinforced by husks treated by alkaline solution and silane have higher bending moduli and stresses than those reinforced by untreated husks and husks treated by silane alone. It can be supposed that the PLA/husks adhesion was enhanced. No difference was observed according to the silane nature.

Keyword:

Rice husk

Einkorn wheat husk

PLA

Silane treatment surface

Alkaline treatment

\section{Introduction}

The rice and wheat grains are coated by husks to protect them during the growing season. Husks are hard materials and they are composed of holocellulose (cellulose and hemicellulose), lignin, silica and wax that impede microbial attack (Bledzki et al., 2010; Khalil, 2008). In most of the cases these husks are incinerated by cereal producers without any energetic valorization despite the abundant volume deposited throughout the world. Because of the large fraction of cellulose present in these husks, they may be considered as potential candidates for the reinforcement of biodegradable composites.

One of the purposes of using husks as fillers is cost reduction as the cost of bio-sourced and biodegradable polymers are still high.

\footnotetext{
* Corresponding author at: School of Textile, Leather and Fashion, Hanoi University of Science and Technology, 1 Dai Co Viet, Hanoi, Viet Nam. Tel.: +84932276988.

E-mail addresses: thao.tranthiphuong1@hust.edu.vn, thotrang215@yahoo.com (T.P.T. Tran), Jean-Charles.Benezet@mines-ales.fr (J.-C. Bénézet)

Anne.Bergeret@mines-ales.fr (A. Bergeret).
}

However like other natural fibres, using husks has drawbacks such as a high hydrophily due to the presence of hydroxyl groups on the husk surface. Furthermore the presence of non-cellulosic components (e.g. lignin and wax) may prevent husks having a good interfacial adhesion with the host polymer. Therefore, chemical treatments for husks are commonly investigated.

An huge amount of researches had been investigated on the modification of natural fibres and their subsequent characterization in composites. Many chemical treatments have been screened to enhance fibre/matrix interface such as alkali treatment (Gomes et al., 2007; Islam et al., 2010), acetylation (Bledzki et al., 2008), silane treatment (Lung et and Matinlinna, 2012), maleation (Park et al., 2004).

Alkali treatment is believed to remove non-cellulosic components away from fibre surface and activates hydroxyl group. However, the surface properties of treated fibres depend on various factors such as the concentration of the alkaline solution, the fibre immersion time and temperature. Oh et al. (2005a,b) reported the effect of the concentration of the alkaline solution and of the temperature on the physicochemical changes and the crystalline structure of pulp sheet. They found that the crystallinity ratio was 
decreased with increasing the alkaline concentration and the cellulose crystal moved from cellulose I to cellulose II for alkaline concentrations over 15\%. Alawar et al. (2009) studied the morphology and tensile properties of alkaline treated palm fibres. In this study, single palm fibres were soaked in alkaline solutions with different concentrations $(0.5 ; 1 ; 1.5 ; 2.5$, and $5 \%)$ and the result showed that the fibres obtained the maximum tensile strength of the single palm fibres by using a $1 \%$ alkaline solution for $1 \mathrm{~h}$ at $100^{\circ} \mathrm{C}$, at higher $\mathrm{NaOH}$ concentrations, the tensile strength of the single palm fibres dropped significantly. The alkali treatment also cleans a large amount of impurities on the fibre surface and as sodium concentration increases, number of pores increases on the fibre surface, this might be attributed to the severity of reaction. In some other researches, an alkaline treatment was use for pineapple leaf fibres in polycarbonate (Threepopnatkul et al., 2009), abaca fibres in polypropylene (PP) (Rahman et al., 2009), kenaf fibres in PLA (Huda et al., 2008), in epoxy resin (Meon et al., 2012; Yousif et al., 2012), and in PP (Asumani et al., 2012), flax fibres in PP (Cantero et al., 2003; Zafeiropoulos et al., 2002) and polyester (Baley et al., 2006), hemp fibres in PLA (Islam et al., 2010), luffa fibres in PP (Demir et al., 2006) and recycled fibres from disposable chopsticks in PLA (Huda et al., 2006). The results showed that alkaline treatments increase the surface roughness that results in a better mechanical interlocking and it increments the amount of cellulose exposed on the fibre surface, thus increasing the number of possible reaction sites. Huda et al. (2008) reported that alkaline treatment improved the compatibility between kenaf fibres and PLA resin. The mechanical properties of PLA/alkaline treated kenaf fibres composites were significantly higher than those of PLA/untreated kenaf fibres composites. Impact strength is increased by $50 \%$ compared to composite with untreated fibres. Flexural modulus and strength are increased by $48 \%$ and $34 \%$, respectively. On the other hand, Valadez-Gonzalez et al. (1999a,b) reported that the treatment by an alkaline solution with a concentration of $2 \%$ for $1 \mathrm{~h}$ did not significantly influence composite mechanical properties in the case of henequen and jute fibres reinforced high density polyethylene. All studies concluded that alkaline treatments remove wax, lignin on the surface of husks, so that it raises the moisture absorption of husk.

In order to reduce the hydrophilic character of cellulose fibres and improve their adhesion properties, bi-functional molecules were often supplied on the fibres surface, leaving one of the functions available for further exploitation. Previous researches were devoted to modification of cellulose fibres using silane coupling agents. The commercially available silanes used for cellulose fibres and presented in literature are numerous (Table 1 ).

It can be observed that $\gamma$-aminopropyltriethoxysilane (named APS) and $\gamma$-glycidoxypropyltrimethoxysilane (named GPS) were widely applied for natural fibre reinforced PLA (Chun et al., 2012; Huda et al., 2008; Yu et al., 2010). Mechanisms were proposed for the reaction taking place at the fibres surface as shown in Fig. 1. The first step consisted in the reaction between alkoxy groups from silane agents and hydroxyl groups on the glucose units of the cellulose molecules in the husks cell-wall leading to a polysiloxane network at the husk surface. Some reactions with lignin hydroxyl groups could also occur. When combined with the PLA matrix, several reactions may occur. Yu et al. (2010) proposed on one hand, a reaction between amine groups from APS and acid end groups of PLA leading to the formation of an amide function (Fig. 1 - Scheme 1 ), and on the other hand, a reaction between epoxy groups from GPS and hydroxyl end groups of PLA occurred leading to the formation of an ether function (Fig. 1 - Scheme 2). Nevertheless the authors did not suggest the possibility of an additional epoxy-acid reaction at the silane/GPS interface (Fig. 1 - Scheme 3).

The interfacial interaction between natural fibre and PLA resin are improved by coupling agent, the mechanical and thermo-mechanical properties composites were significantly higher than those of the PLA matrix itself. Huda et al. (2008) treated kenaf fibres by APS and incorporated with PLA to fabric laminated composites. The flexural modulus of composite is increased from 5.6 GPa for untreated fibres to $9.5 \mathrm{GPa}$ for silane treated fibres (a 69\% increase). This result suggests that APS may be a good coupling agent for husk and PLA also.

This study is divided in three main parts. The first part deals with the influence of an alkaline treatment on the morphology, the colour, the chemical composition and the surface properties of rice and Einkorn wheat husks. In the second part, the influence of two commonly used silane agents (APS and GPS) grafted on rice and Einkorn wheat husks and husks previously treated with an alkaline solution was studied. The last part concerns the influence of all these treatments on PLA/husks biocomposites properties in comparison with literature.

\section{Materials and methods}

\subsection{Materials}

The poly (lactic acid) PLA 7000D was supplied by Nature-Works LLC with the following characteristics: $\mathrm{Mn}=179200 \mathrm{Da}$, polydispersity index $\mathrm{I}=1.75\left(\mathrm{SEC}, \mathrm{THF}, \mathrm{T}=25^{\circ} \mathrm{C}\right), \mathrm{Tg}=58^{\circ} \mathrm{C}$ and $\mathrm{Tm}=152^{\circ} \mathrm{C}$ (DSC, $10^{\circ} \mathrm{C} / \mathrm{min}$, nitrogen atmosphere).

The long-grain rice husks (genus Oryza, noted R) are supplied by SOUFFLET S.A. (France) and Einkorn wheat husks (genus Triticum Monococcum - noted W) are supplied by TOFAGNE S.A. (France). The husking process and the characteristics of these husks were detailed in a previous publication (Bergeret et al., 2013). $\gamma$-aminopropyltriethoxysilane (named APS) and $\gamma$ glycidoxypropyltrimethoxysilane (named GPS) were supplied by Sigma-Aldrich (France).

\subsection{Processing conditions}

PLA pellets and untreated and treated husks were dried under vacuum at $50^{\circ} \mathrm{C}$ for $24 \mathrm{~h}$ before processing. Compounding was achieved by twin screw extruder (Clextral BC21 $900 \mathrm{~mm}$ ). The temperature profile screw is the following: $60^{\circ} \mathrm{C}$ (feeder) $/ 120^{\circ} \mathrm{C} / 170$ ${ }^{\circ} \mathrm{C} / 180^{\circ} \mathrm{C} / 180^{\circ} \mathrm{C} / 180^{\circ} \mathrm{C} / 180^{\circ} \mathrm{C} / 180^{\circ} \mathrm{C} / 180^{\circ} \mathrm{C} / 180^{\circ} \mathrm{C} / 180^{\circ} \mathrm{C} / 180^{\circ} \mathrm{C}$ $/ 180^{\circ} \mathrm{C} / 180^{\circ} \mathrm{C}$ die). The speed rate was kept at $250 \mathrm{rpm}$ and the feed rate was $4 \mathrm{~kg} / \mathrm{h}$. A dry blend of the PLA and husks was introduced through two feeders. The husk weight content was $20 \%$. After compounding, granules were dried under vacuum at $50^{\circ} \mathrm{C}$ for $24 \mathrm{~h}$. Injection moulding was then carried out on a Krauss Maffei KM50-T180CX. Temperature was set at $200^{\circ} \mathrm{C}$ and the mould temperature was maintained at $40^{\circ} \mathrm{C}$.

\subsection{Procedures for husk surface modifications}

\subsubsection{Alkaline treatment procedure}

To study the effect of sodium hydroxide concentration on husks, $\mathrm{R}$ and $\mathrm{W}$ were dried at $100^{\circ} \mathrm{C}$ in vacuum for $24 \mathrm{~h}$ until reaching a constant weight $(\mathrm{m} 1)$ then immersed in sodium hydroxide $(\mathrm{NaOH})$ solutions at 2,5 and $10 \%$, for $24 \mathrm{~h}$ at room temperature. To study the effect of treatment duration on the husk, $\mathrm{R}$ and $\mathrm{W}$ were immersed in sodium hydroxide solution ( $5 \%$ ) for $6 \mathrm{~h}, 12 \mathrm{~h}, 18 \mathrm{~h}, 24 \mathrm{~h}$ and $48 \mathrm{~h}$ at room temperature. The husks were washed in running tap water to eliminate $\mathrm{NaOH}$, and then the husks were washed with acetic acid (1\%). Finally, the husks were washed again by tap water. After washing, the husks were dried through a two-steps process: (i) highly wet husks were first kept in air for 3 days to reduce significantly the water content, and (ii) then husks were dried at $100^{\circ} \mathrm{C}$ in an 
Table 1

Silanes used for the natural fibres/polymer composites in the literature.

\begin{tabular}{|c|c|c|c|c|}
\hline Silane & Abbreviation & Target matrix & Target fibres & Ref. \\
\hline \multirow[t]{7}{*}{$\gamma$-aminopropyltriethoxy silane } & \multirow[t]{7}{*}{ APS } & Polypropylene & Luffa & Demir et al. (2006) \\
\hline & & Poly acid lactic & Ramie & Yu et al. (2010) \\
\hline & & & Coconut shell & Chun et al. (2012) \\
\hline & & & Kenaf & Huda et al. (2008) \\
\hline & & Polycarbonate & Pineapple & Threepopnatkul et al. (2009) \\
\hline & & Epoxy & Microfibrillated cellulose & Lu et al. (2008) \\
\hline & & $*$ & Cellulose fibres & Abdelmouleh et al. (2004) \\
\hline \multirow[t]{4}{*}{$\gamma$-glycidoxypropytrimethoxy silane } & \multirow[t]{4}{*}{ GPS } & Poly acid lactic & Ramie & Yu et al. (2010) \\
\hline & & Epoxy & Microfibrillated cellulose & Lu et al. (2008) \\
\hline & & & Kenaf & Sgriccia et al. (2008) \\
\hline & & & Hemp & Sgriccia et al. (2008) \\
\hline \multirow[t]{3}{*}{$\gamma$-Methacryloxypropytrimethoxy silane } & \multirow[t]{3}{*}{ MPS } & Polycarbonate & Pineapple & Threepopnatkul et al. (2009) \\
\hline & & Low density polyethylene (LDPE) & Cellulose fibre & Abdelmouleh et al. (2007) \\
\hline & & & Cellulose fibres & Abdelmouleh et al. (2004) \\
\hline$\gamma$-(trimethoxysilyl)-1-propanethiol silane & TMPS & Polypropylene & Luffa & Demir et al. (2006) \\
\hline Hexadecyltrimethoxy silane & HTS & Low density polyethylene (LDPE) & Cellulose fibre & Abdelmouleh et al. (2007) \\
\hline \multirow[t]{2}{*}{$\gamma$-mercaptoproyltrimethoxy silane } & \multirow[t]{2}{*}{ MRPS } & Low density polyethylene (LDPE) & Cellulose fibre & Abdelmouleh et al. (2007) \\
\hline & & $*$ & Cellulose fibres & Abdelmouleh et al. (2004) \\
\hline Vinyltris (2-methoxy-ethoxy) silane & VMS & Hight density polyethylene (HDPE) & Henequen & Valadez-Gonzalez et al. (1999a,b) \\
\hline Triethoxy-vinyl silane & TVS & Poly acid lactic & Chopstick & Shih et al. (2010) \\
\hline
\end{tabular}

* The matrix is not presented in the articles.

oven under vacuum for $6 \mathrm{~h}$ to obtain a constant weight $(\mathrm{m} 2)$. The weight percent loss (WPL) of husks was calculated from Eq. (1):

$\mathrm{WPL}=\frac{(m 1-m 2)}{m 1} \times 100$

\subsubsection{Silane treatment procedure}

$1 \mathrm{wt} . \%$ of silane (weight percentage compared to the husks) was dissolved in water/ethanol mixture $(30 / 70 \mathrm{w} / \mathrm{w})$. The $\mathrm{pH}$ of the solution was adjusted to 4 with acetic acid and stirred continuously during $30 \mathrm{~min}$. Next, the husks were soaked in solution for $3 \mathrm{~h}$, washed by tap water and dried through a two-steps process: (i) highly wet husks were first kept in air for 3 days, and (ii) then husks were oven dried at $60^{\circ} \mathrm{C}$ for $24 \mathrm{~h}$.

\subsubsection{Procedure for combined alkaline and silane treatments}

A combination of alkaline and silane treatments was carried on. In this case before silane treatment, husks were treated by $\mathrm{NaOH}$ with a given concentration of $5 \%$ for $24 \mathrm{~h}$. Table 2 lists all the treatments that were applied on husks in this study.

\subsection{Methods for husks and biocomposites characterizations}

\subsubsection{Microscopic observations}

The husks surfaces before and after treatment were observed by an environmental scanning electron microscope (ESEM) Quanta FEG 200, equipped with an OXFORD Inca 350 energy dispersive $\mathrm{X}$-ray microanalysis (EDX) system. The ESEM operated at an accelerating voltage of $15 \mathrm{kV}$.

Table 2

Nomenclature used for untreated and treated husks.

\begin{tabular}{rllll}
\hline $\begin{array}{l}\text { Concentration of } \\
\mathrm{NaOH}(\%)\end{array}$ & APS & GPS & $\begin{array}{l}\text { Abbreviations for Einkorn } \\
\text { wheat husk (W) and } \\
\text { long-grain rice husk (R) }\end{array}$ \\
\hline 0 & No & No & W & R \\
2 & No & No & WN2 & RN2 \\
5 & No & No & WN5 & RN5 \\
10 & No & No & WN10 & RN10 \\
0 & Yes & No & WA & RA \\
5 & Yes & No & WNA & RNA \\
0 & No & Yes & WG & RG \\
5 & No & Yes & WNG & RNG \\
\hline
\end{tabular}

\subsubsection{Determination of husks composition}

The method to analyze the husk composition was adopted from the work of Bledzki et al. (2008). It can be divided into three steps that are the followings: (ash)

1st step: determination of the inorganic compound content

$2 \mathrm{~g}$ of dried of husk were put in oven at $600^{\circ} \mathrm{C}$ for $8 \mathrm{~h}$ and then cooled until room temperature. The weight of ash is $w 1(\mathrm{~g})$, and the ratio of ash in husk was calculated by Eq. (2):

Ash $(A)(\%)=\frac{w 1}{2} \times 100$

The ash elements composition was determined by ESEM-EDX.

2nd step: determination of the extractible content

$5 \mathrm{~g}$ of dried husk were introduced in an extraction thimble and then in a Soxhlet extraction unit. A mixture of ethanol and toluene $(50 / 50 \mathrm{v} / \mathrm{v})$ was used as solvent and extraction process continued for $18 \mathrm{~h}$. Then, ethanol/toluene was changed to ethanol $99 \%$ and the extraction process continued for $6 \mathrm{~h}$. After extraction, the sample was dried up to constant weight $(w 2)$ at $100^{\circ} \mathrm{C}$. The extractive was calculated by Eq. (3):

Extractive $(E)(\%)=\frac{5-w 2}{5} \times 100$

3rd step: determination of lignin and holocellulose contents.

$1.5 \mathrm{~g}$ of the previously extracted sample was put in a flask with $125 \mathrm{ml}$ of de-ionized water. $1 \mathrm{ml}$ of glacial acetic acid and $1 \mathrm{~g}$ of sodium chlorite were added successively. The flask was put in a water bath and heated up to $70^{\circ} \mathrm{C}$ for $2 \mathrm{~h}$ and $1 \mathrm{ml}$ glacial acetic acid and $1 \mathrm{~g}$ of sodium chlorite were introduced. This last addition of acetic acid and sodium chlorite was repeated several times. Finally, the holocellulose was filtered, washed and dried in an oven up to constant weight at $100^{\circ} \mathrm{C}$. The whole process should ideally be repeated until the husk turn white in colour and the weight does not decrease further. The weight of sample at the end of process $(w 3)$ is the weight of holocellulose.

The ratio of lignin in the husk was calculated by Eq. (4):

$\operatorname{Lignin}(L)(\%)=\frac{(1.5-w 3)(1-E)}{1.5} \times 100-A$

where $A$ is the ratio of ash in husk calculated by Eq. (2); $E$ is the ratio of wax in husk calculated by Eq. (3). 


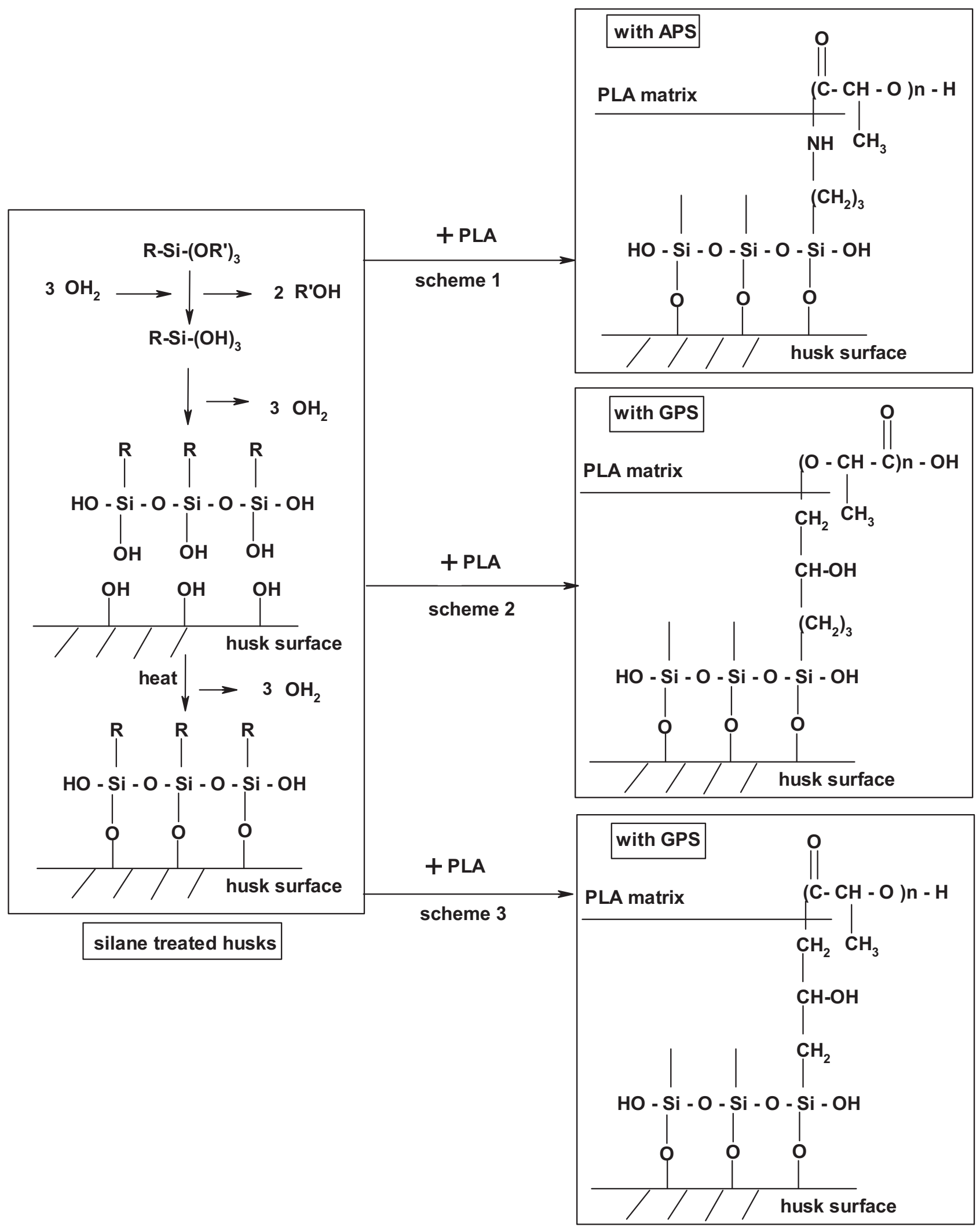

Fig. 1. Chemical mechanisms at the interfacial area between silane (Scheme 1: APS and Schemes 2 and 3: GPS) treated natural fibres and PLA matrix. Eq. (5)

The ratio of holocellulose in the husk was calculated by

Holocellulose $(H)(\%)=\frac{(w 3)(1-E)}{1.5} \times 100$

\subsubsection{Surface energy}

Contact angles of husks were performed using Digidrop apparatus (GBX Instruments) with an automatic system for the liquid droplet formation. Husks were considered as solids. About $300 \mathrm{mg}$ of husk were compressed under a force $10 \mathrm{kN}$ during $5 \mathrm{~min}$ to 
product a pellet sample with the diameter $13 \mathrm{~mm}$. The wetting liquids used was diiodomethane, formamide and water. For each liquid three measurements were performed. In order to determine the polar and the dispersive components of the surface free energy the approach proposed by Owens et and Wendt (1969) has been used (Eq. (6)):

$\gamma_{L}(1+\cos \theta)=2 \sqrt{\gamma_{S}^{d}} \sqrt{\gamma_{L}^{d}}+2 \sqrt{\gamma_{S}^{p}} \sqrt{\gamma_{L}^{p}}$

where the subscripts $L$ and $S$ are related respectively to the liquid and the solid states, and $d$ and $p$ to the dispersive and polar characters.

\subsubsection{Moisture absorption}

$3 \mathrm{~g}$ dried husks were stored at $20^{\circ} \mathrm{C} 65 \% \mathrm{RH}$ until the weight was stabilized (w4). The moisture absorption (MA) of husk was calculated by Eq. (7):

$M A=\frac{w 4-3}{3} \times 100(\%)$

\subsubsection{FTIR measurements}

FTIR was used to determine changes in chemical functional groups of $\mathrm{R}$ and $\mathrm{W}$ before and after treatment. $\mathrm{R}$ and $\mathrm{W}$ were grinded to dust and then were mixed with $\mathrm{KBr}$ to make a pellet sample concentration in $\mathrm{KBr}$ ( 3 wt.\%). Each spectrum was recorded in the MIR range with a Bruker IFS 66 device, at a resolution of $4 \mathrm{~cm}^{-1}$, the scan ranging from 4000 to $500 \mathrm{~cm}^{-1}$ and a total of 32 scans were averaged.

\subsubsection{Mechanical properties of composites}

Mechanical properties of composites were measured by a Zwick Z010. The samples were stored at room temperature under standard atmospheric conditions $\left(22-24^{\circ} \mathrm{C}\right)$ for $24 \mathrm{~h}$ before testing. At least 5 specimens were used for each test to ensure the reproducibility.

Strength tests were measured according to the ISO 572-1 standard (load cell: $2.5 \mathrm{kN}$; crosshead speed: $50 \mathrm{~mm} / \mathrm{min}$ for break properties, $1 \mathrm{~mm} / \mathrm{min}$ for tensile modulus). The specimen had a dog-bone geometry with a $200 \mathrm{~mm}$ length and central dimensions of $10 \times 4 \mathrm{~mm}^{2}$ (Sample $1 \mathrm{~A}$ according to ISO 527-2).

Three-point-bending tests were followed standard ISO 178:2001. Sample size was $80 \times 10 \times 4 \mathrm{~mm}^{3}$, load cell was $2.5 \mathrm{kN}$ and the crosshead speed was $2 \mathrm{~mm} / \mathrm{min}$.

\subsubsection{Thermogravimetric analysis (TGA) experiments}

Thermogravimetric analyses were carried out using a Perkin Elmer equipment (Pyris1 TGA) to study the influence of husks surface treatments on the thermal stability of husks themselves and of PLA/husks biocomposites. The samples were scanned from 25 to $600^{\circ} \mathrm{C}$ at a heating rate of $10^{\circ} \mathrm{C} / \mathrm{min}$ in the presence of nitrogen.

\section{Results and discussion}

\subsection{Alkaline treatment of husks}

\subsubsection{Surface morphology of alkaline treated husks}

Husks surfaces before alkaline treatment were observed by ESEM and discussed in a previous paper (Bergeret et al., 2013). It was observed that the outer surface of untreated rice husk was highly ridged and that the ridges included peaks and valleys interlay regularly (Fig. 2a). On the contrary the outer surface of untreated wheat husks was flat and presented tiny knots scattered (Fig. 2e). Further investigations through EDX measurements have showed the presence of silica. For rice husks, a silicon-cellulose membrane is present at the outer surface and formed a natural protective layer against termites and other micro-organisms that may attack on the paddy (Ndazi et al., 2007). As concerns wheat husks, it was not observed any silicon-cellulose membrane on the outer surface but white knots containing silica near the outer surface were presented.

After $\mathrm{NaOH}$ treatment, the surface morphology of both husks is modified. As concerns rice husks, some small holes appear on the outer surface (for a $\mathrm{NaOH}$ concentration of $2 \%$ ) (Fig. 2b). There are more holes and these holes are larger for a $\mathrm{NaOH}$ concentration of $5 \%$ (Fig. 2c). When using a $10 \% \mathrm{NaOH}$ solution, rice husks are destroyed (Fig. 2d) and the surfaces has a lot of large holes and breaks. With a $\mathrm{NaOH}$ concentration of $2 \%$, the surface of wheat husk appears many little gutter parallel, the knot change to white colour (Fig. 2f). It may be predicted that wheat husk have a very thin film of lignin covering the surface, and this film was dissolved easily by $\mathrm{NaOH}$ at low concentrations. When the $\mathrm{NaOH}$ concentration increased (5 and 10\%), the white knots on the wheat husks surface were smaller and some of them disappeared (Fig. $2 g$ and $h$ ).

Therefore, it can be concluded from ESEM observations that $\mathrm{NaOH}$ treatment leads to an increase in the surface roughness of the husks that is induced by a partial dissolution of some components of husks and this dissolution seems to be more and more important when the concentration of the $\mathrm{NaOH}$ solution increases. Ndazi et al. (2007) also observed that the roughness of outer and inner surfaces of rice husks did not change significantly after an alkaline treatment $(2 \% \mathrm{NaOH})$, and that changes started to be substantial wearing of asperities on the outer surface and particle cracking only after treated with a $\mathrm{NaOH}$ solution at a 4 and $8 \%$ concentration. Further investigations will determine the global weight loss of alkaline treated husks and the nature of the dissolved fractions.

\subsubsection{Global weight loss of husks after alkaline treatments}

Natural fibres are mainly composed of cellulose, hemicellulose, lignin and wax. Hemicellulose corresponds to several sugar molecules which are soluble in water or alkaline solutions. The structure of lignin is similar to that of unsaturated aromatic polymers and it may be soluble in an alkaline solution (Nguyen Tri Phuong et al., 2010). Therefore hemicellulose and lignin may partially dissolve during an alkaline treatment, leading to a decrease in husks weights. Fig. 3a shows the influence of alkaline concentration on rice and wheat husks weight loss after treatment duration of $24 \mathrm{~h}$ at room temperature. Results show that the greater the alkaline concentration, the higher the weight loss and that the alkaline concentration have more influence on wheat than on rice husk. It is worthy to note that the weight loss of wheat husk is higher than that of rice husk at 5 and $10 \% \mathrm{NaOH}$ concentration. Fig. $3 \mathrm{~b}$ shows the influence of alkaline treatment time on the weight loss of husks for a given $\mathrm{NaOH}$ concentration (5\%). It was found that the weight loss increases significantly during the first $18 \mathrm{~h}$ of treatment, and then the change in weight loss was not significant. This results are agreement with the results of Sun et al. (1995), that showed that wheat straw weight loss is about $40 \%$ for an alkaline treatment at a $\mathrm{NaOH}$ concentration of $1.5 \%$ at $20^{\circ} \mathrm{C}$ for about $18-24 \mathrm{~h}$, and then, the weight of wheat straw did not change. Nguyen Tri Phuong et al. (2010) found also that weight percent loss of bamboo fibres treated by a $0.5 \mathrm{M}$ alkaline solution increased significantly during the first $15 \mathrm{~h}$ and then began to stabilize after treatment. However, the maximum weight percent loss of bamboo fibres is only about $12 \%$, nearly three times lower than that of rice husk, wheat husk and wheat straw. This result may be explained by the high cellulose content of bamboo fibres.

\subsubsection{Chemical composition of husks after the alkaline treatment}

Table 3 shows the repartition of inorganic compound, hemicellulose, lignin and wax within the different alkaline treated husks for $24 \mathrm{~h}$. Before treatment, wheat and rice husks contain about $2 \%$ of waxes that help the husk to be waterproofed and protect the grains. After alkaline treatment, waxes are removed. Untreated rice husks 


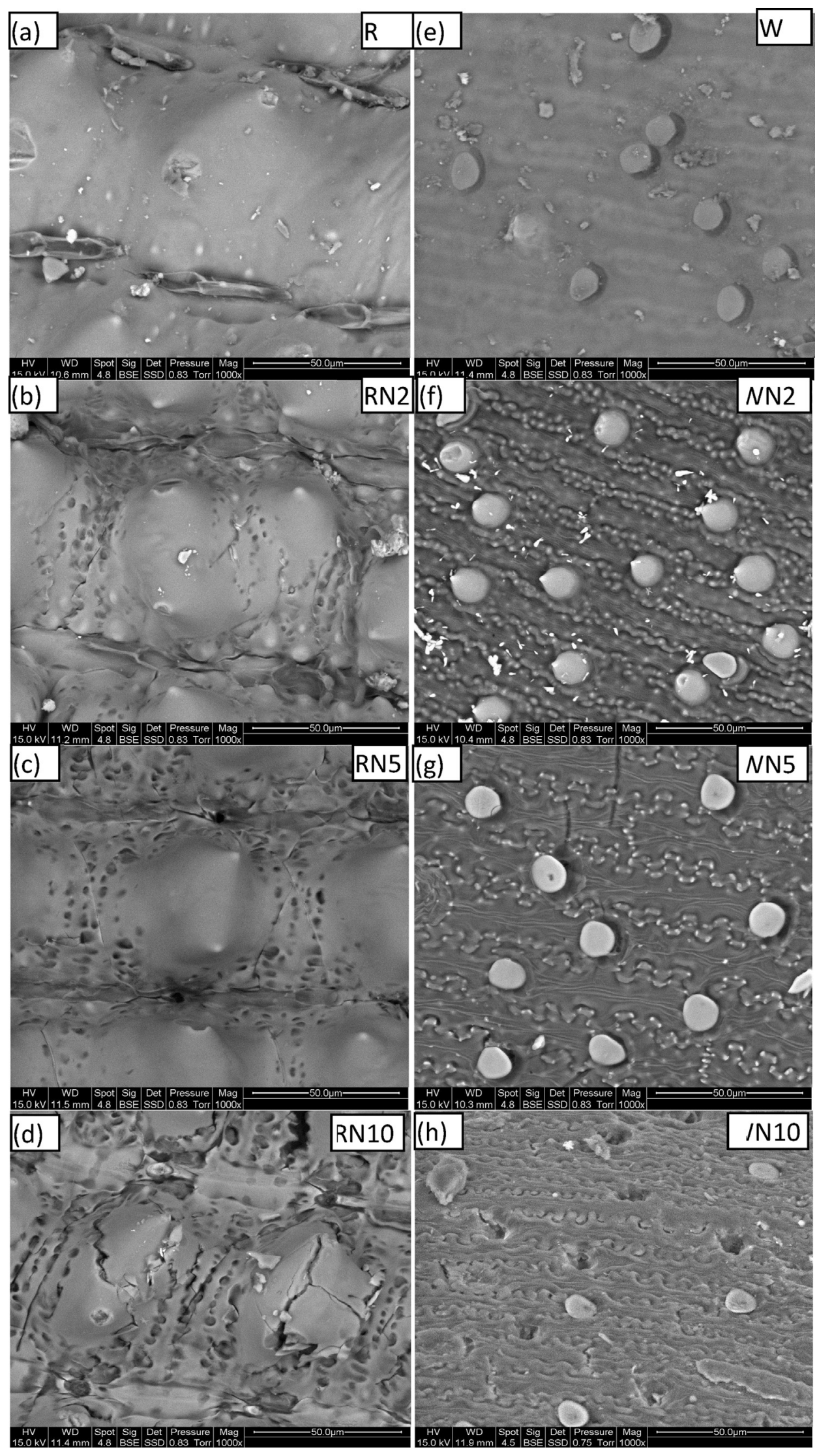

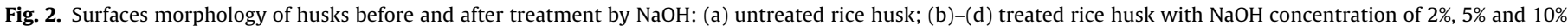
respectively; (e) untreated wheat husk; (f)-(h) treated wheat husk with $\mathrm{NaOH}$ concentration of $2 \%, 5 \%$ and $10 \%$, respectively. 

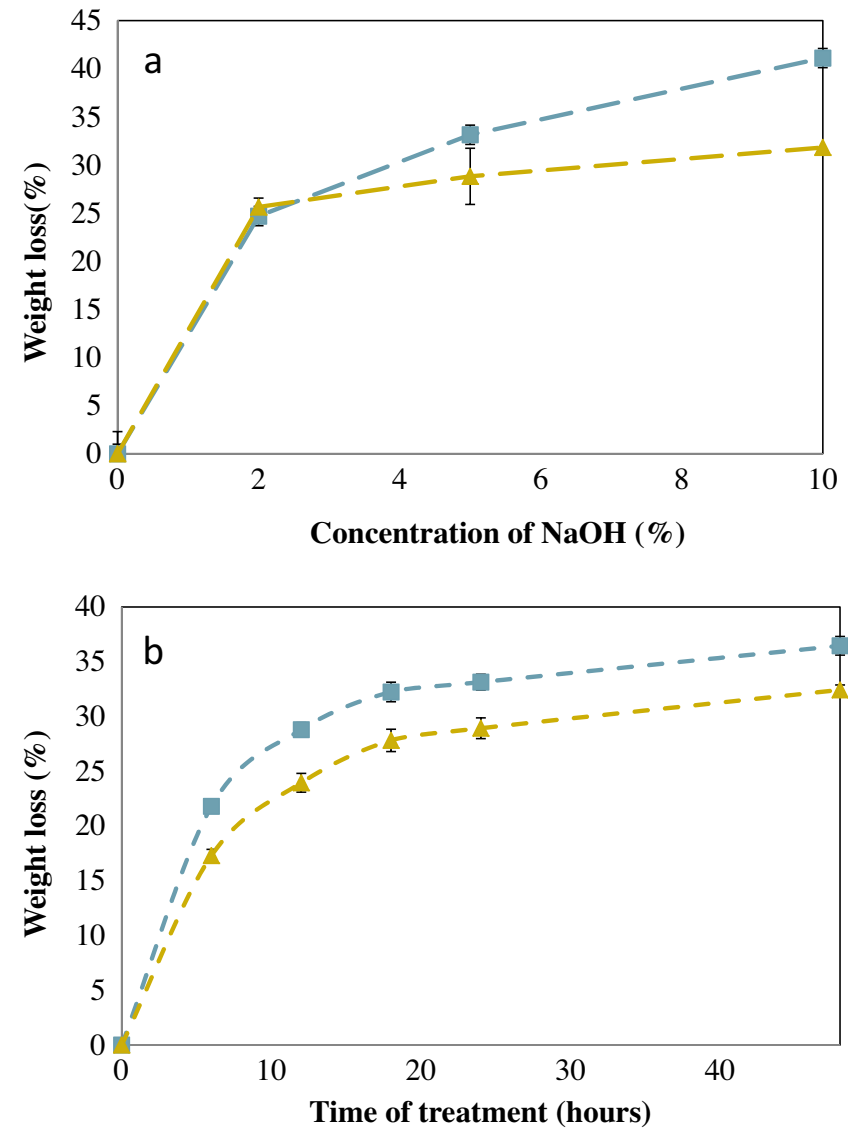

Fig. 3. Weight loss of Einkorn wheat and rice husks as a function of the alkaline treatment conditions: (a) influence of the alkaline concentration for a $24 \mathrm{~h}$ treatment and of (b) the treatment time with an alkaline concentration of $5 \%$.

Table 3

Husks compositions (\%) as a function of the $\mathrm{NaOH}$ concentration for an alkaline treatment duration of $24 \mathrm{~h}$

\begin{tabular}{lrrrr}
\hline Husk composition & \multicolumn{1}{c}{ R } & \multicolumn{1}{c}{ RN2 } & \multicolumn{1}{c}{ RN5 } & \multicolumn{1}{c}{ RN10 } \\
\hline Wax & $2.2 \pm 0.9$ & $0.8 \pm 0.4$ & $0.7 \pm 0.6$ & $0.5 \pm 0.4$ \\
Lignin & $37.1 \pm 2.7$ & $38.2 \pm 1.4$ & $39.9 \pm 0.4$ & $27.4 \pm 1.3$ \\
Holocellulose & $46.3 \pm 1.4$ & $49.8 \pm 0.8$ & $52.0 \pm 0.2$ & $65.1 \pm 0.6$ \\
Inorganic (ash) & $14.3 \pm 0.2$ & $11.2 \pm 0.2$ & $7.5 \pm 0.1$ & $6.9 \pm 0.0$ \\
& & & & \\
Husk composition & \multicolumn{1}{c}{$\mathrm{W}$} & $\mathrm{WN} 2$ & \multicolumn{1}{c}{ WN5 } & WN10 \\
\hline Wax & $2.0 \pm 0.0$ & $0.8 \pm 0.7$ & $1.3 \pm 1.2$ & $1.2 \pm 1.1$ \\
Lignin & $28.3 \pm 0.8$ & $22.9 \pm 0.9$ & $17.8 \pm 0.9$ & $16.2 \pm 1.3$ \\
Holocellulose & $63.0 \pm 1.0$ & $72.0 \pm 0.5$ & $76.5 \pm 0.6$ & $78.2 \pm 0.6$ \\
Inorganic (ash) & $6.7 \pm 1.4$ & $4.3 \pm 0.1$ & $4.5 \pm 0.2$ & $4.4 \pm 0.0$ \\
\hline
\end{tabular}

contain about $46 \%$ of holocellulose that is much lower than that of untreated wheat husks (about 63\%). After alkaline treatment, this amount is increased. The increase in the holocellulose content of RN10 is about $19 \%$ compared to R and those of WN10 is about $15 \%$ compared to W. As concerns lignin and inorganic components such as silica, a decrease is observed. According to literature it can be assumed that silica in raw rice husks is bonded to organic material (Huda et al., 2006), so that when the lignin was dissolved, silica was removed also.

The ash content of rice husk decreased a half from $14.3 \pm 0.2 \%$ to $7.5 \pm 0.1 \%$ for RN5, and then it decreased slightly for RN10. The $\mathrm{NaOH}$ concentrations do not have much influence on the ash content of wheat husk. This results reveal that the alkaline solution dissolve more inorganic components of rice husk than of wheat husk.
Table 4

Atomic composition of husk ashes (\%).

\begin{tabular}{lrrrr}
\hline Element & \multicolumn{1}{c}{ R } & \multicolumn{1}{c}{ RN2 } & \multicolumn{1}{c}{ RN5 } & \multicolumn{1}{c}{ RN10 } \\
\hline Carbon (C) & $3.44 \pm 0.37$ & $3.92 \pm 0.58$ & $3.75 \pm 1.46$ & $3.15 \pm 0.22$ \\
Oxygen (O) & $52.75 \pm 0.01$ & $51.94 \pm 0.42$ & $51.34 \pm 0.17$ & $51.57 \pm 0.32$ \\
Sodium (Na) & $0.38 \pm 0.26$ & $2.77 \pm 0.06$ & $3.82 \pm 0.25$ & $4.10 \pm 0.04$ \\
Silicon (Si) & $37.47 \pm 0.84$ & $32.68 \pm 0.03$ & $31.00 \pm 1.10$ & $31.63 \pm 0.62$ \\
Calcium (Ca) & $1.79 \pm 0.14$ & $6.42 \pm 0.09$ & $7.83 \pm 0.06$ & $7.58 \pm 0.43$ \\
& & & & \\
Element & W & WN2 & WN5 & WN10 \\
\hline Carbon (C) & \multicolumn{1}{c}{$3.96 \pm 0.24$} & $4.40 \pm 0.24$ & $4.77 \pm 0.02$ & $5.24 \pm 0.26$ \\
Oxygen (O) & $52.38 \pm 0.01$ & $48.40 \pm 0.02$ & $49.05 \pm 0.21$ & $49.02 \pm 0.02$ \\
Sodium (Na) & 0.00 & $9.64 \pm 0.36$ & $9.23 \pm 0.18$ & $18.42 \pm 0.08$ \\
Silicon (Si) & $35.77 \pm 0.75$ & $28.20 \pm 0.41$ & $27.38 \pm 0.33$ & $17.22 \pm 0.28$ \\
Calcium (Ca) & $2.31 \pm 0.04$ & $6.17 \pm 0.28$ & $6.72 \pm 0.15$ & $7.60 \pm 0.15$ \\
\hline
\end{tabular}

The ash of husks consists in inorganic components, which are not degradable at $600^{\circ} \mathrm{C}$ for $18 \mathrm{~h}$. The atomic compositions of ashes are listed in Table 4. High amounts of silicon (35-38\%) in ashes were found whatever the untreated husk considered. This amount is reduced with the increase of $\mathrm{NaOH}$ concentration (about $-16 \%$ for rice husk and $-52 \%$ for wheat husk for a $\mathrm{NaOH}$ concentration of $10 \%$ ). These differences could be explained by the previously description of the husk surface morphology after alkaline treatment (Fig. 2). Indeed for rice husks, the surfaces have a lot of large holes however the silicon-cellulose membrane still exists. On the opposite, the wheat husks surfaces have tiny holes that replaced white knots of silica.

As concerns the other atoms it can be observed no significant variations in carbon and oxygen whatever the $\mathrm{NaOH}$ concentration and husk nature. A slight increase in sodium and calcium quantity after alkaline treatment is observed. It is well known that alkaline treatment have an effect on the cellulose structure, the crystallinity and the polymorphic transformation (from cellulose type I to cellulose type II) (Oh et al., 2005a,b). During an alkaline treatment process, sodium goes deeply into the structure of cellulose. It can be assumed that the washing process only removes sodium on the husk surface, and not sodium deep inside the structure of the husk. It causes the increase of sodium quantity in husk ash after any alkaline treatment. Absorption of calcium from carbonates of water can also be supposed. Wheat husk always absorbs more sodium and in mean proportion calcium than rice husk, may be due to the content of holocellulose of wheat husk which is always higher than those of rice husk.

\subsubsection{FTIR analysis of alkaline treated husks}

3.1.4.1. Comparison of untreated wheat and rice husks. The various chemical constituents present in untreated and alkali treated rice husk and Einkorn wheat husk were analyzed by FTIR (Fig. 4). It can be observed that rice husk ( $\mathrm{R}$ spectrum) and wheat husk (W spectrum) have similar FTIR spectra because of equivalent chemical composition. The hydrophilic tendency of both $\mathrm{R}$ and $\mathrm{W}$ husks was reflected in the broad absorption band $\left(3100-3700 \mathrm{~cm}^{-1}\right)$, which was ascribed to the strong hydrogen-bonded $\mathrm{OH}$ stretching present in aliphatic or aromatic alcohols and present in their main components. The two peaks at about $2920 \mathrm{~cm}^{-1}$ are due to the $\mathrm{C}-\mathrm{H}$ stretching from aliphatic saturated compounds, i.e. aliphatic moieties in cellulose and hemicellulose. The shoulder peak at about $1735 \mathrm{~cm}^{-1}$ is assigned to the stretching vibrations of the $\mathrm{C}=\mathrm{O}$ function of the acetyl and ester group of hemicellulose or waxes and natural fatty components (Seki, 2009). The peak at about $1650 \mathrm{~cm}^{-1}$ is assigned to $\mathrm{H}-\mathrm{O}-\mathrm{H}$ bending of absorbed water (Sun et al., 1995). The most characteristic infrared bands of lignin are found at about $1510 \mathrm{~cm}^{-1}$ representing the $\mathrm{C}=\mathrm{C}$ aromatic skeletal vibrations (Abdelmouleh et al., 2007; Shih et al., 2010; Valadez-Gonzalez et al., 1999a,b). The bands in the 

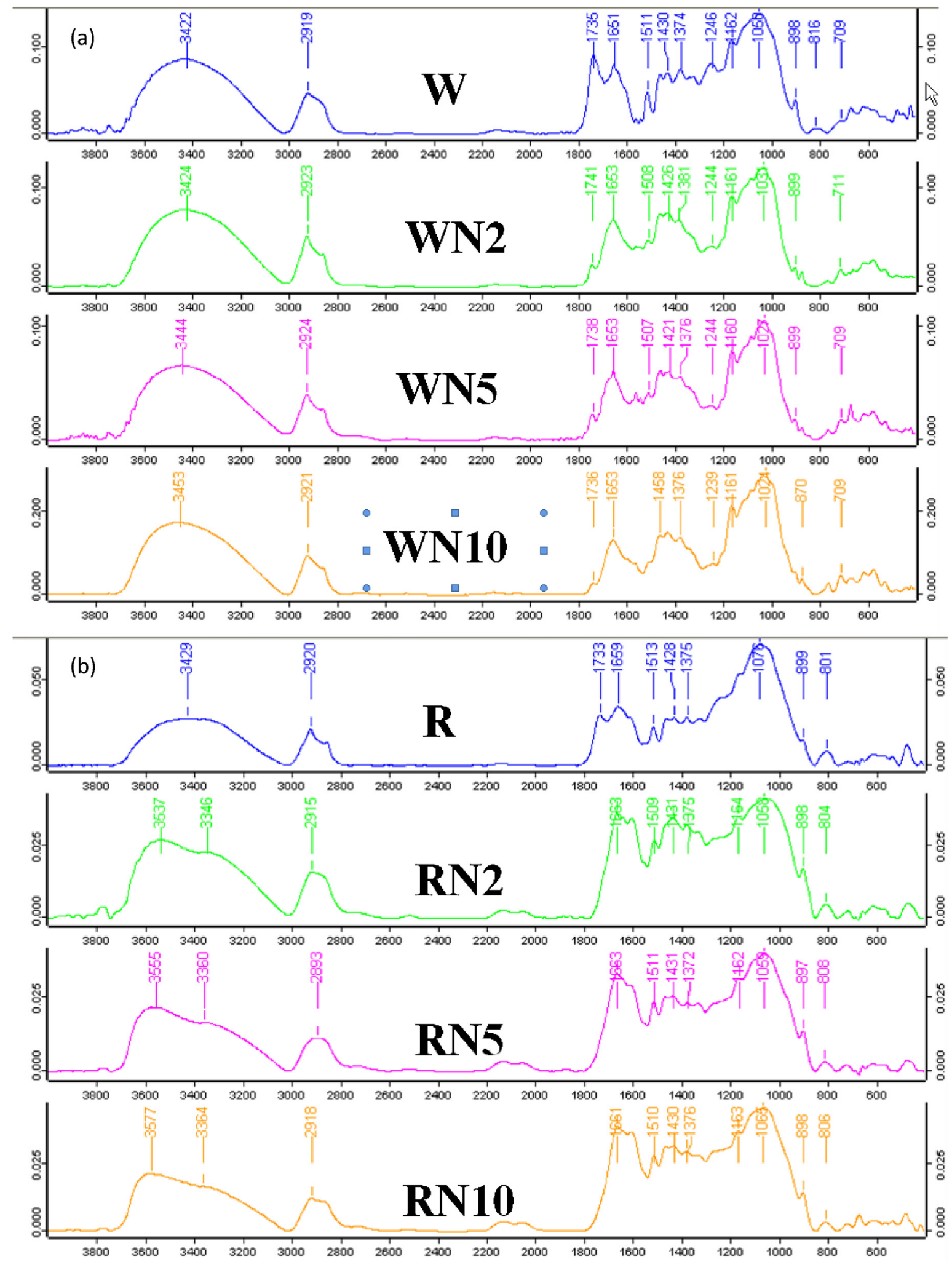

Fig. 4. FTIR spectra of untreated and alkaline treated wheat husk (a) and rice husk (b) at different $\mathrm{NaOH}$ concentrations (2, 5 and $10 \%$ ).

range of $1430-1460 \mathrm{~cm}^{-1}$ were distributed to $\mathrm{C}-\mathrm{H}$ deformation (asymmetric) and aromatic skeletal vibration (Sun et al., 1995) and the bands in the range of $1375-1350 \mathrm{~cm}^{-1}$ were assigned to the symmetric and asymmetric $\mathrm{C}-\mathrm{H}$ deformations in methyl and phenolic alcohol or C-H rocking in alkanes (Bledzki et al., 2012, 2014). The peak at about $1245 \mathrm{~cm}^{-1}$ is ascribed to $\mathrm{C}-\mathrm{O}$ deformation in secondary alcohol and aliphatic ether. The large band in the range $1160-900 \mathrm{~cm}^{-1}$ is attributed to asymmetric and symmetric $\mathrm{Si}-\mathrm{O}-\mathrm{C}$ and $\mathrm{Si}-\mathrm{O}-\mathrm{Si}$ stretching bonds corresponding to silica present in cereal husks used in this study. The absorbance bands at about $800 \mathrm{~cm}^{-1}$ are commonly ascribed to the stretching vibrations of the $\mathrm{Si}-\mathrm{C}$ bonds. 


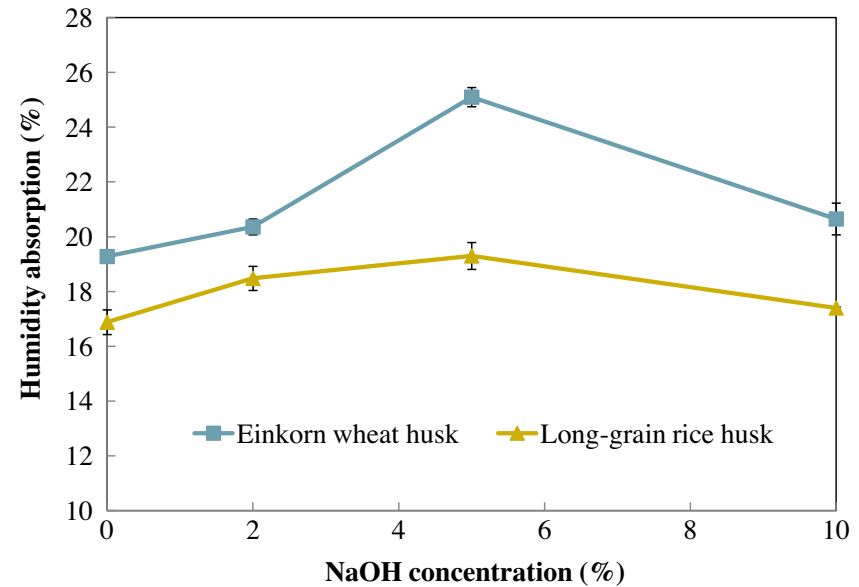

Fig. 5. Moisture absorption of wheat husk and rice husk as a function of the $\mathrm{NaOH}$ concentration.

3.1.4.2. Influence of the $\mathrm{NaOH}$ concentration. For wheat husk treated at different $\mathrm{NaOH}$ concentrations (WN2, WN5 and WN10), the large peak assigned to hydrogen-bonded $\mathrm{OH}$ stretching is shifted to higher wavenumbers (from 3420 for $\mathrm{W}$ to $3453 \mathrm{~cm}^{-1}$ for WN10) at higher $\mathrm{NaOH}$ concentrations as shown in Fig. 4a. For rice husk treated at different $\mathrm{NaOH}$ concentrations (RN2, RN5 and RN10), the shape this large peak is changed and two peaks located at around $3550 \mathrm{~cm}^{-1}$ and $3360 \mathrm{~cm}^{-1}$ can be distinguished. This difference may be due to different lignin contents between both husks. Moreover these two peaks are shifted towards higher wavenumbers when the $\mathrm{NaOH}$ concentration increased in relation with the variations in the lignin content (Table 3). (Oh et al., 2005a,b). For both rice and wheat husks, the absorption band at about $1735 \mathrm{~cm}^{-1}$ decreases after any alkaline treatment. This peak was corresponding to waxes and natural fatty components that are removed after the alkaline treatment as observed from chemical composition analyses (Table 3) (Ndazi et al., 2007). And the band about $1650 \mathrm{~cm}^{-1}$ assigned to $\mathrm{H}-\mathrm{O}-\mathrm{H}$ bending of absorbed water seems to grow up, which agreed with the increased moisture absorption of both rice and wheat husk after alkaline treatment (Fig. 4). The absorption band located at about $1510 \mathrm{~cm}^{-1}(\mathrm{C}=\mathrm{C}$ phenolic vibrations) and in the range $1160-900 \mathrm{~cm}^{-1}(\mathrm{Si}-\mathrm{O}-\mathrm{C}$ and $\mathrm{Si}-\mathrm{O}-\mathrm{Si}$ stretching bands) decreases both with increased concentrations of $\mathrm{NaOH}$ for wheat husks, as they remain at the same wavelengths for rice husks. This result is in agreement with the lignin and silica content measurements (Table 4) that show a higher residual content of lignin and silica for rice husks than for wheat husk. The absorbance band at about $800 \mathrm{~cm}^{-1}$ ascribed to the $\mathrm{Si}-\mathrm{C}$ stretching vibrations (Enescu et al., 2009) disappears after alkaline treatment for wheat husk. This is another evidence of the possibility for $\mathrm{NaOH}$ to react with silica on the surface wheat husk. On the contrary these peaks remains in the case of rice husks showing that the silica amount on the surface of rice husk is greater than that of wheat husk, so that, alkaline treatments cannot dissolve completely silica on the rice husk surface. These results are also in agreement with ESEM observations.

\subsubsection{Moisture absorption of alkaline treated husks}

Fig. 5 shows the influence of alkaline treatment on the moisture absorption of the husk.

Wheat husks have higher moisture absorption rate than rice husks. This can be explained by the higher holocellulose content of wheat husks compared to rice husks. Both husks reach to maximum absorption after treatment for a $\mathrm{NaOH}$ concentration of $5 \%$. This evolution could be related to two consecutive phenomena occurring according to the alkaline concentration. For low $\mathrm{NaOH}$

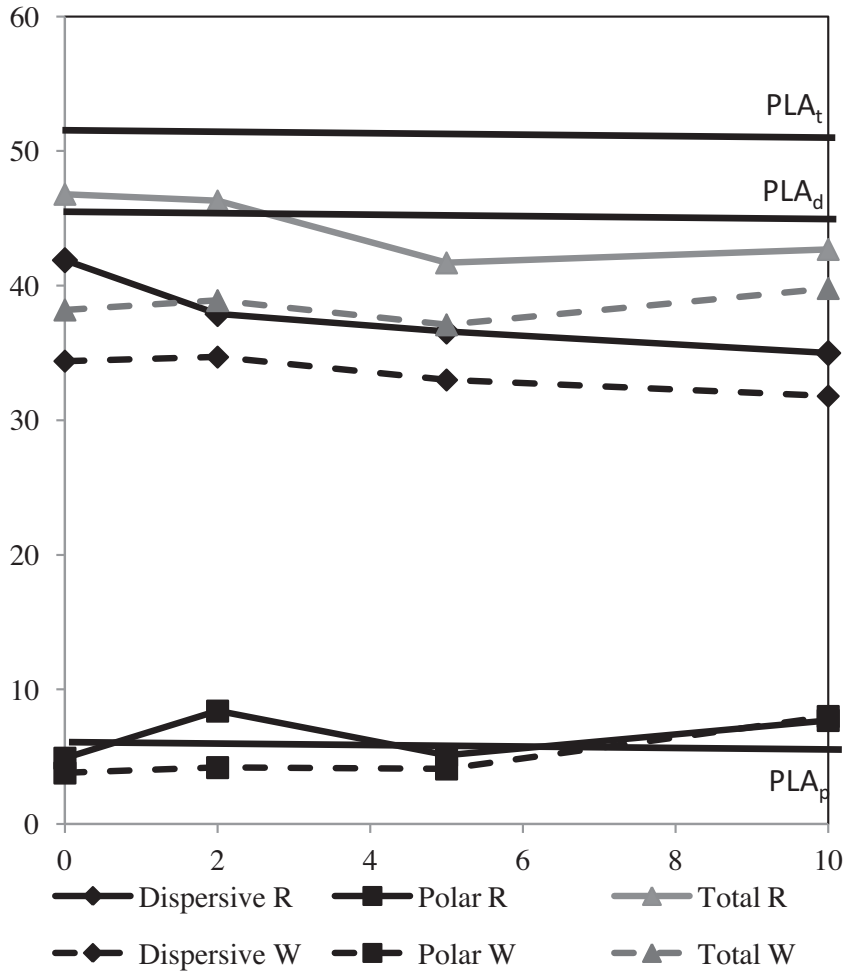

Fig. 6. Surface energy and its polar and dispersive components of rice and wheat husks as a function of the $\mathrm{NaOH}$ concentration.

concentrations, a partial removal of lignin and waxes may occur leading to an activation of hydroxyl surface groups and therefore an increase in the moisture absorption. For high $\mathrm{NaOH}$ concentrations, alkaline treatments may mainly modify the crystallinity and polymorphic transformation (form cellulose type I to cellulose type II) (Oh et al., 2005a,b) so that the husk surface is less polar and the moisture absorption rate slightly decreases.

\subsubsection{Surface energy of alkaline treated husks}

Fig. 6 shows the influence of different alkaline treatments on the dispersive and polar components of the surface energy of the husks in comparison to PLA. For PLA, polar and dispersive components are 5.7 and $45.1 \mathrm{~mJ} / \mathrm{m}^{2}$, respectively. The corresponding values are 4.9 and $41.9 \mathrm{~mJ} / \mathrm{m}^{2}$ for untreated rice husk (R) and 3.8 and $34.4 \mathrm{~mJ} / \mathrm{m}^{2}$ for untreated wheat husk (W). As the polar and dispersive components of $\mathrm{R}$ are closer to those of PLA than those of $\mathrm{W}$, it can be said that the R/PLA interfacial adhesion is better compared to W/PLA. Moreover as the difference between the surface free energy of the husks and of the PLA is greater for the $W$ than for the $\mathrm{R}$, it can be concluded that the wetting by PLA is better for W than for R. Nevertheless a previous study (Bergeret et al., 2013) has shown no significant difference in mechanical properties according to the husk nature when untreated.

It can be seen a reduction in the dispersive component of the surface energy of both husks when the $\mathrm{NaOH}$ concentration increased. Alkaline treatment seems to have more influence on the dispersive component of the rice husks (decrease by $-16 \%$ between R and R20) than of the wheat husks (decrease by $-7 \%$ between $\mathrm{W}$ and W20). For wheat husks an increase in the polar component is observed as a discontinuous evolution is obtained for rice husks. As a result an increase by $10 \%$ in the surface energy is revealed for wheat husks as no significant variation is given in evidence for rice husks.

It is well known that the dispersive component is related to the ability for creating Van der Waals interfacial interactions at the solid surface and the polar component to the ability for settling acid-base 
interfacial interactions at the solid surface. Wax and lignin include hydrophobic and aromatic groups. As alkaline treatment removes wax and lignin, the number of hydroxyl groups may increase, leading to an increase in the polar component and a decrease in the dispersive component of the surface energy. Gassan and Gutowski (2000) observed also an increase in the polar components of jute fibres after corona and UV treatments.

\subsubsection{Conclusion on alkaline treatments}

This first part showed that after an alkaline treatment, some components of rice and wheat husks have been removed such as waxes, lignin and silica. On the opposite, an increase in the holocellulose content was observed. A global higher weight loss was obtained for wheat husk compared to rice husk with a quite stabilization for $\mathrm{NaOH}$ concentration over $5 \%$ and a treatment duration of $24 \mathrm{~h}$ (for a $\mathrm{NaOH}$ concentration of 5\%). The increase in hollocellulose content induced a greater water sensibility after alkaline treatment especially at low $\mathrm{NaOH}$ concentration with a maximum point for a $\mathrm{NaOH}$ concentration of $5 \%$. The alkaline treatment resulted also in variations in the surface energy properties with a decrease in the dispersive component and an increase in the polar component leading to a global decrease in total surface energy so that an improvement of the wetting by PLA is expected. This evolution is more effective for rice husk.

\subsection{Silane treatment of husks}

As already shown, the major components of husks include cellulose, hemicellulose, lignin and wax. Cellulose is resistant to strong alkali but is easily hydrolyzed by acid. Hemicellulose is very hydrophilic, soluble in alkali and easily hydrolyzed in acids. Lignin is not hydrolyzed by acids, but soluble in hot alkali, readily oxidized and easily condensable with phenol (John et and Thomas, 2008). In the second step of this paper, the husks were treated by $1 \mathrm{wt} . \%$ of silane dissolved in a water/ethanol mixture $(30 / 70 \mathrm{w} / \mathrm{w})$. This solution cannot dissolve cellulose, hemicelluloses and lignin, may be only remove the waxes from the surface of the husk. Therefore the morphology of the husk surface and the chemical component of husks did not change after a silane treatment. So that, the results of this part are only focused on the modification of the husks surface energy of the moisture absorption and of the colour of the husks after silane treatments.

\subsubsection{FTIR analysis of silane treated husks}

FTIR spectra of APS and GPS are presented in Fig. 7, both APS and GPS present three peaks at about 2975, 2945 and $2840 \mathrm{~cm}^{-1}$ that are corresponding to $\mathrm{C}-\mathrm{H}$ symmetric and asymmetric stretching vibrations. The bands in the range $1000-1200 \mathrm{~cm}^{-1}$ (1167 and $1080 \mathrm{~cm}^{-1}$ for APS and 1194 and $1087 \mathrm{~cm}^{-1}$ for GPS) are clearly attributed to Si-O-Si vibrations. The peaks at $957 \mathrm{~cm}^{-1}$ for APS and $910 \mathrm{~cm}^{-1}$ for GPS are assigned to silanol groups produced in the silane hydrolysis (Lu et al., 2008). Finally the peaks at $790 \mathrm{~cm}^{-1}$ for APS and $822 \mathrm{~cm}^{-1}$ for GPS are related to stretching vibrations of the $\mathrm{Si}-\mathrm{C}$ bonds (Chun et al., 2012).

The spectrum of APS presents also a small peak at $3377 \mathrm{~cm}^{-1}$ revealing a $\mathrm{C}-\mathrm{NH}_{2}$ bond according to Threepopnatkul et al. (2009). Weak bands at 1560 and $1443 \mathrm{~cm}^{-1}$ are typical of the amine group that are strongly hydrogen bonded to the hydroxyl groups of silanols in agreement with the study of Lu et al. (2008). Spectra of silane treated rice and wheat husks are presented in Fig. 7b and c, respectively. As rice husk and wheat husk contain $14.5 \%$ and $6.6 \%$ respectively of silica (Table 4 ) it will hide bands assigned to the stretching of the $\mathrm{Si}-\mathrm{O}-$ Cellulose bands demonstrating that a reaction occurred between silane agents and the husk surface. Moreover the bands related to both silanes overlap with those of husks so that characteristic peaks of APS and GPS could not be detected by IR.

Wheat husk after silane treatment present a peak at $711 \mathrm{~cm}^{-1}$ for WA and WG and $708 \mathrm{~cm}^{-1}$ for WNA and WNG. This peak is also higher sharper for WNA and WNG, it reveals that pre-treatment by alkaline promote silanes react with the husks. The FTIR spectra of RNA and RNG presented smalls peaks at 667 and $668 \mathrm{~cm}^{-1}$, these peaks could be assigned to $\mathrm{Si}-\mathrm{C}$ stretching.

\subsubsection{Moisture absorption of silane treated husks}

The influence of surface treatments on the moisture absorption of husks is showed in Fig. 8. In a previous paper on untreated husks (Bergeret et al., 2013) it was shown that the higher the lignin content the higher the hydrophobicity that explain the difference between untreated rice and wheat husks. When husks were treated by APS and GPS no change in the moisture absorption was observed for wheat husks as a slight decrease for rice husks. After an alkaline pre-treatment an increase in the moisture absorption was obtained. This moisture absorption decreased when husks are treated with silane agents. The silane treatments have more influence on wheat husk than on rice husk. The decrease of moisture absorption of husk after silane treatment may be explained by the chemical reaction in Fig. 1. Indeed silanes react with the hydroxyl group on the glucose units of the cellulose molecules in the husks cell-wall, so that the ability absorption of husk is decreased. As wheat husk contain more holocellulose than rice husk, and as alkaline treatment removes more lignin and silica on the surface of wheat husk than rice husk. A greater number of hydroxyl groups are present on the wheat husk surface and then reaction the silanes are emphasized.

\subsubsection{Surface energy of silane treated husks}

Fig. 9 shows the influence of silanes treatment on the polar and dispersive components of the surface energy of the husks. It can be observed that silane treatment increased the dispersive component ( $+31 \%$ for APS and $+28 \%$ for GPS) of the surface energy of wheat husk. As concerns rice husk just a slight increase $(+3 \%)$ is obtained for APS and a slight decrease $(-4 \%)$ for GPS so that it can be concluded that both silanes have negligible influence on the dispersive component. Because of the low values of the polar components it is difficult to conclude about their variations. As a result, no variation in the surface energy is observed for rice husk as an increase is given in evidence for wheat husk ( $+27 \%$ for APS and $+20 \%$ for GPS). The differences between rice and wheat husks may be due to a greater number of hydroxyl groups present on the wheat husk surface because of higher contents of lignin and silica removed from the surface after the alkaline pre-treatment. Differences between APS and GPS may be due to a more effective reactivity of APS towards cellulose than GPS.

\subsection{Properties of biocomposites}

\subsubsection{Mechanical properties}

Table 5 shows the influence of different surface treatments on the mechanical properties of PLA reinforced by rice husks and Einkorn wheat husks.

The results show that the husks treated with only the $\mathrm{NaOH}$ aqueous solution does not improve the flexural and tensile strength (reduction by $50-60 \%$ and $35-40 \%$ for bending and tensile strengths, respectively). Gomes et al. (2007) reported also that the tensile strength of $10 \mathrm{wt} \%$ alkaline treated curaua fibres is much lower than that of untreated fibres. This lost in strength after an alkaline treatment may be due to a lower interfacial adhesion between PLA and alkaline treated husks that can be confirmed by the dispersive components of W5 and R5 that is less close from PLA than W and R (Fig. 6). 

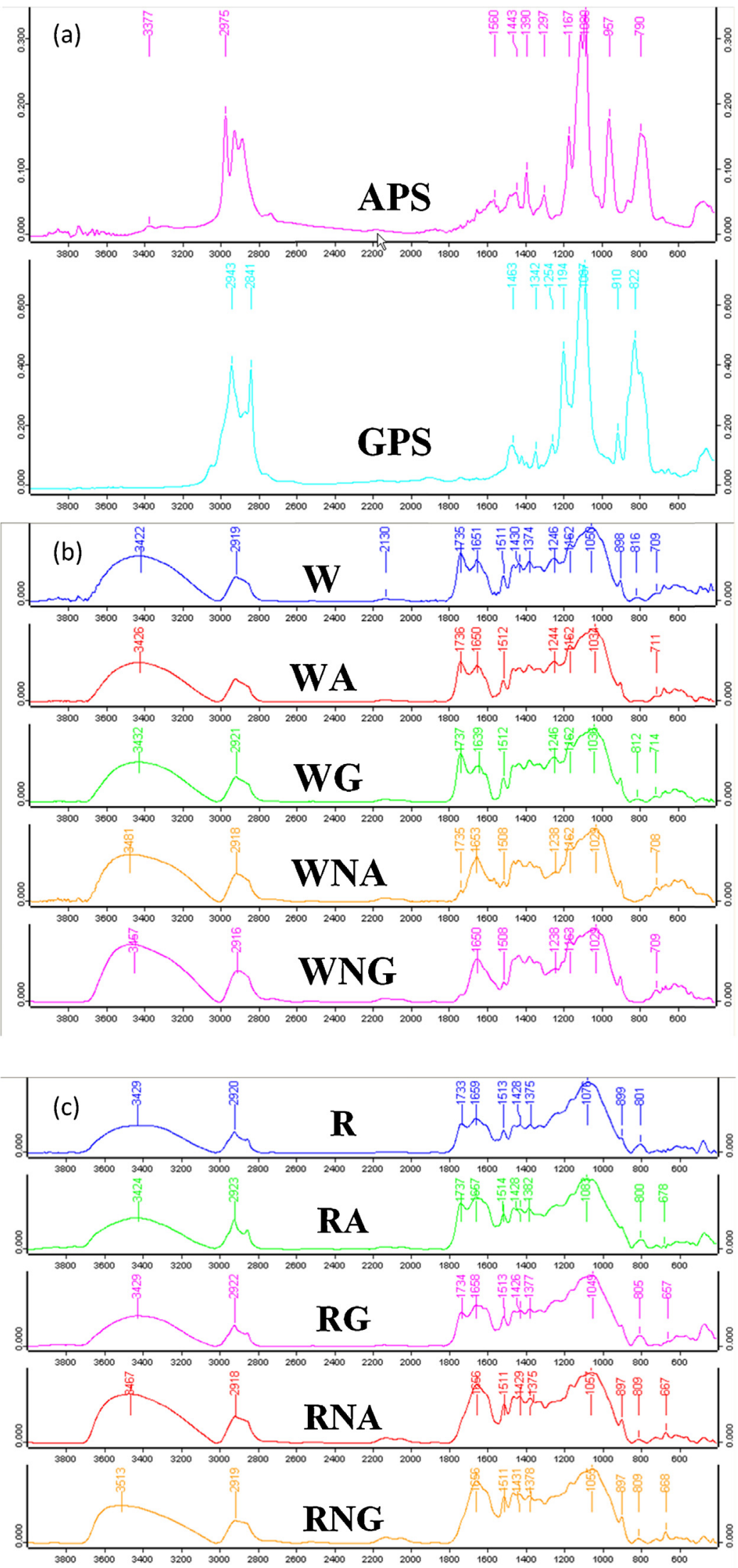

Fig. 7. FTIR spectra of pure APS and GPS (a), untreated and silane treated wheat husk (b) and rice husk (c). 


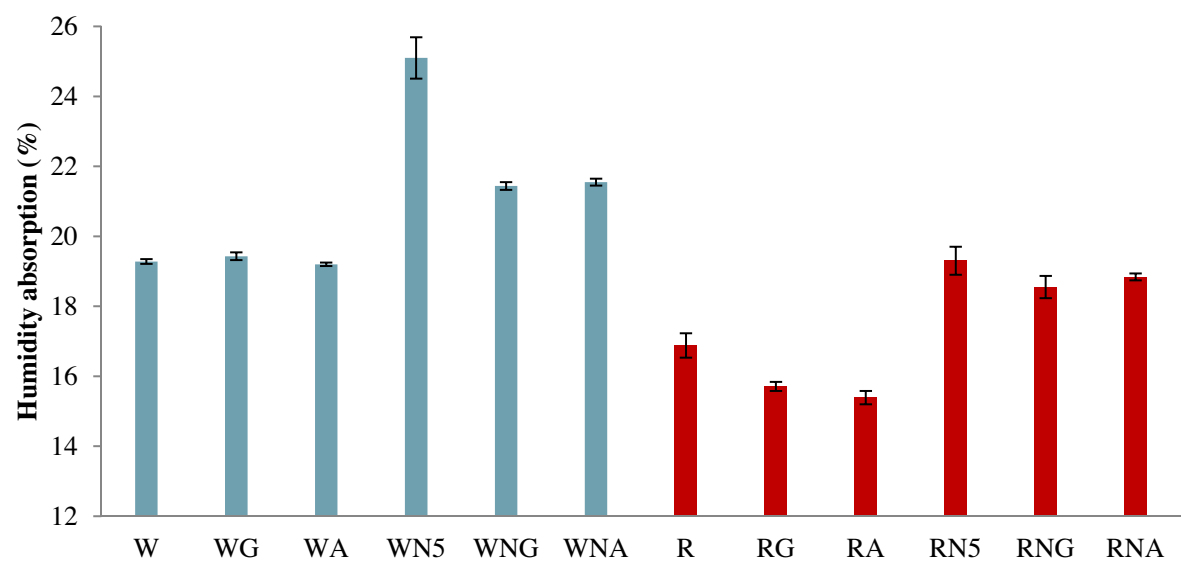

Fig. 8. Moisture absorption of silane treated husks $\left(20^{\circ} \mathrm{C}, 65 \%\right.$ R.H $)$.

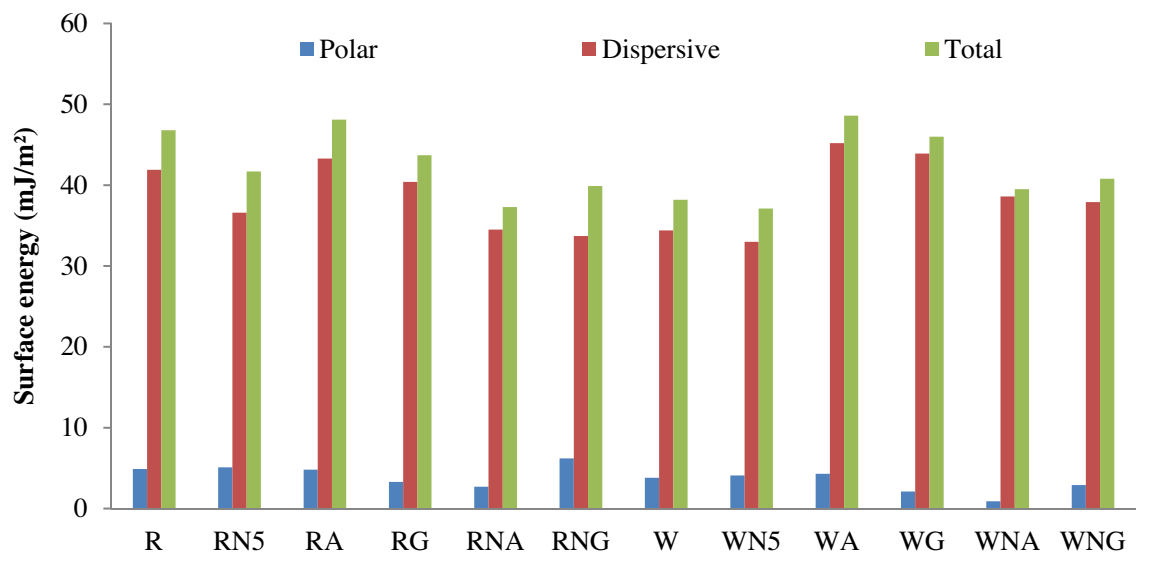

Fig. 9. Surface energy and its polar and dispersive components of rice and wheat husks as a function of the silane treatment.

Table 5

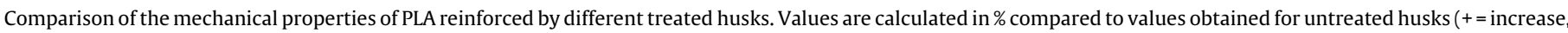
- = decrease).

\begin{tabular}{|c|c|c|c|c|c|c|}
\hline & \multicolumn{2}{|c|}{ Bending modulus } & \multicolumn{2}{|c|}{ Bending strength } & \multicolumn{2}{|c|}{ Tensile strength } \\
\hline & Wheat husk & Rice husk & Wheat husk & Rice husk & Wheat husk & Rice husk \\
\hline WN5/RN5 & +6.4 & +5.7 & -58.4 & -50.7 & -36.0 & -38.5 \\
\hline WA/RA & +7.5 & -3.9 & +8.4 & +8.4 & -1.6 & -6.5 \\
\hline WNA/RNA & +8.0 & -5.7 & +20.1 & +10.9 & +9.7 & +6.6 \\
\hline WG/RG & +8.0 & -3.0 & +11.0 & +5.7 & +1.8 & -3.7 \\
\hline WNG/RNG & +7.7 & -2.8 & +17.8 & +10.5 & +5.8 & +4.7 \\
\hline
\end{tabular}

Higher bending strengths are obtained for husks treated with APS ( $+8.4 \%$ for both RA and WA husks) and GPS ( $+11 \%$ and $+5.7 \%$ for WG and RG respectively) that confirms the occurring of interfacial reaction such as those described in Fig. 9. As wheat husks contain a higher quantity of holocellulose than rice husks, a greater surface reactivity with silanes may be in agreement with the higher increase obtained for wheat husks compared to rice husk. Opposite phenomena were observed by Huda et al. (2008). These authors obtained a decrease by $60 \%$ of the flexural strength of the PLA/kenaf fibres biocomposites with the addition $40 \mathrm{wt} . \%$ of kenaf fibres, but an increase by $50 \%$ when kenaf fibres are treated by APS. The bending modulus of biocomposites containing treated wheat husk increases by about $7-8 \%$, while those of treated rice husk decrease by about $3-5 \%$ whatever the silane used.

It is worth noting that the combination of both alkaline and silane treatments gives the highest performances compared to individual treatments. It may be explained by the fact that, after the alkaline treatment, the hydrogen bonding network within the cellulose structure may be broken and the hydroxyl groups of cellulose may become more active and therefore improve the hydrophilic of the husks as well as their compatibility with the silane agents.

\subsubsection{Thermal properties of biocomposites}

The thermal stability of neat PLA and PLA reinforced with untreated and treated husks was investigated by TGA. Results for rice husks and wheat husks are similar, so that only the results for rice husk are shown in Fig. 10. Thermal degradation of PLA involved a single step degradation mechanism occurring at $360^{\circ} \mathrm{C}$. Biocomposite with untreated rice husks shows a lower degradation temperature $\left(340^{\circ} \mathrm{C}\right)$ than PLA due to a decrease of average molecular weight of PLA when biocomposites are processed by extrusion as shown in a previous study (Bergeret et al., 2013).

Thermal degradation temperatures of the biocomposites reinforced by silane treated husks (RA, RG) and by alkaline then 


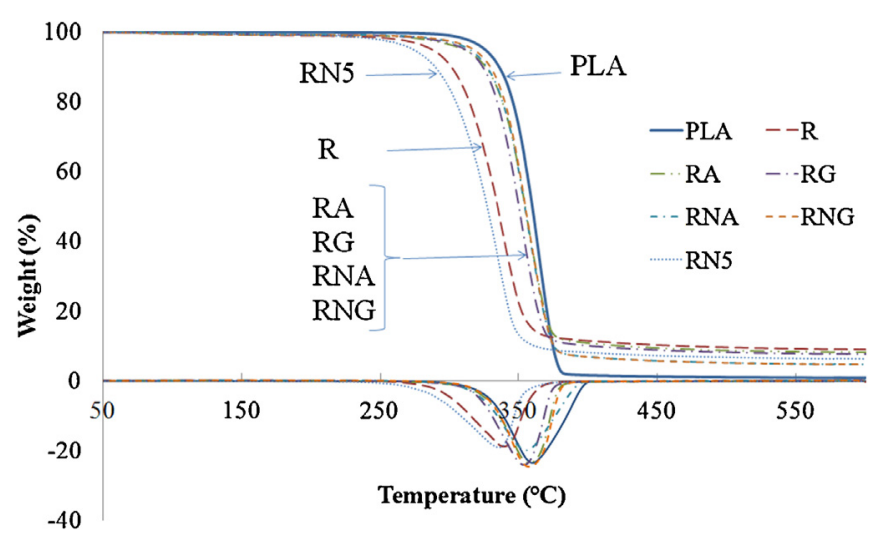

Fig. 10. Thermogravimetric curves of the neat PLA and biocomposites with untreated and treated rice husk.

silane treated husks (RNA, RNG) increase to about $354-357^{\circ} \mathrm{C}$. This temperature is only slightly lower than that of neat PLA, and significantly higher than that of the biocomposite with untreated husks. The chemical bond between PLA matrix and the husk could enhance the interfacial adhesion and the thermal degradation temperature increases consequently (Lee et and Wang, 2006; Yu et al., 2010). However, the thermal degradable temperature of the composites with alkaline treated rice husks $\left(336^{\circ} \mathrm{C}\right)$ is lower than that of the composites with silane treated husks. It may be indicated that the stability of the interface bond between alkaline treated husks and PLA is less effective than that of the interface bond between silane treated husks and PLA (Yu et al., 2010). This phenomenon is in agreement with the loss of mechanical properties of biocomposites in Section 3.3.1.

\section{Conclusion}

Different surface treaments including alkaline treatments with $\mathrm{NaOH}$ solutions at different concentrations and silane agents ( $\gamma$-aminopropyltriethoxysilane (APS) and $\gamma$ glycidoxypropyltrimethoxysilane (GPS)) on the characteristics of rice and wheat husks were investigated.

It is observed that alkaline treatments dissolved wax, lignin and silica. Husks after alkaline treatments have a higher sensitivity to moisture, and lower surface energies. Nevertheless alkaline treatments did not improve the mechanical properties of biocomposites.

When husks are treated with silane agents, results show a decrease in the moisture absorption compared to untreated and alkaline treated husks. An increase in the energy surface of husks and in the mechanical properties and the thermal stability of biocomposites were obtained. Better results were obtained with APS agent compared to GPS agent because of a higher reactivity, the group amine of APS shows more effect on PLA than group epoxy of GPS.

When silane treatments are combined with an alkaline pretreatment, biocomposites have higher mechanical properties and thermal stability than biocomposites with only silane treated. Alkali treatment cleans the surface of husk and active the hydroxyl groups. These active hydroxyl groups react with the silanes more easily than the hydroxyl group on the surface of untreated husks.

It is also given in evidence that wheat husks (with higher cellulose content) lead to better performances when they are incorporated within PLA than rice husks.

The future works may be focus on the influence of the treatment surface on the aged resistance of biocomposite.

\section{Acknowledgement}

The authors would like to thank the Vietnamese Government (Governmental project N_322) for financial support of this work.

\section{References}

Abdelmouleh, M., Boufi, S., Belgacem, M.N., Duarte, A.P., Ben Salah, A., Gandini, A. 2004. Modification of cellulosic fibres with functionalised silanes: development of surface properties. Int. J. Adhes. Adhes. 24 (1), 43-54.

Abdelmouleh, M., Boufi, S., Belgacem, M.N., Dufresne, A., 2007. Short naturalfibre reinforced polyethylene and natural rubber composites: effect of silane coupling agents and fibres loading. Compos. Sci. Technol. 67 (7-8), 1627-1639.

Alawar, A., Hamed, A.M., Al-Kaabi, K., 2009. Characterization of treated date palm tree fiber as composite reinforcement. Compos. B: Eng. 40 (7), 601-606.

Asumani, O.M.L., Reid, R.G., Paskaramoorthy, R., 2012. The effects of alkali-silane treatment on the tensile and flexural properties of short fibre non-woven kenaf reinforced polypropylene composites. Compos. A: Appl. Sci. Manuf. 43 (9), 1431-1440.

Baley, C., Busnel, F., Grohens, Y., Sire, O., 2006. Influence of chemical treatments on surface properties and adhesion of flax fibre-polyester resin. Compos. A: Appl. Sci. Manuf. 37 (10), 1626-1637.

Bergeret, A., Benezet, J.C., Tran, T.P.T., Papanicolaou, G.C., Koutsomitopoulou, A. 2013. Valorization of agricultural by-products in poly(lactic acid) to develop biocomposites. In: Thakur, V.K. (Ed.), Green Composites from Natural Resources.

Bledzki, A.K., Mamun, A.A., Lucka-Gabor, M., Gutowski, V.S., 2008. The effects of acetylation on properties of flax fibre and its polypropylene composites. Express Polym. Lett. 2 (6), 413-422.

Bledzki, A.K., Mamun, A.A., Volk, J., 2010. Physical, chemical and surface properties of wheat husk, rye husk and soft wood and their polypropylene composites. Compos. A: Appl. Sci. Manuf. 41 (4), 480-488.

Bledzki, A.K., Mamun, A.A., Bonnia, N.N., Ahmad, S., 2012. Basic properties of grain by-products and their viability in polypropylene composites. Ind. Crops Prod. 37 (1), 427-434

Bledzki, A.K., Mamun, A.A., Volk, J., 2014. Barley husk and coconut shell reinforced polypropylene composites: the effect of fibre physical, chemical and surface properties. Compos. Sci. Technol..

Cantero, G., Arbelaiz, A., Llano-Ponte, R., Mondragon, I., 2003. Effects of fibre treatment on wettability and mechanical behaviour of flax/polypropylene composites. Compos. Sci. Technol. 63 (9), 1247-1254

Chun, K.S., Husseinsyah, S., Osman, H., 2012. Mechanical and thermal properties of coconut shell powder filled polylactic acid biocomposites: effects of the filler content and silane coupling agent. J. Polym. Res. 19 (5), 1-8.

Demir, H., Atikler, U., Balköse, D., TIhmInlIoglu, F., 2006. The effect of fiber surface treatments on the tensile and water sorption properties of polypropylene-luffa fiber composites. Compos. A: Appl. Sci. Manuf. 37 (3), 447-456.

Enescu, D., Hamciuc, V., Ardeleanu, R., Cristea, M., Ioanid, A., Harabagiu, V., Simionescu, B.C., 2009. Polydimethylsiloxane modified chitosan. Part III: Preparation and characterization of hybrid membranes. Carbohydr. Polym. 76 (2), $268-278$.

Gassan, J., Gutowski, V.S., 2000. Effects of corona discharge and UV treatment on the properties of jute-fibre epoxy composites. Compos. Sci. Technol. 60 (15), 2857-2863.

Gomes, A., Matsuo, T., Goda, K., Ohgi, J., 2007 août. Development and effect of alkali treatment on tensile properties of curaua fiber green composites. Compos. A: Appl. Sci. Manuf. 38 (8), 1811-1820.

Huda, M.S., Drzal, L.T., Mohanty, A.K., Misra, M., 2006. Chopped glass and recycled newspaper as reinforcement fibers in injection molded poly(lactic acid) (PLA) composites: a comparative study. Compos. Sci. Technol. 66 (11-12), 1813-1824

Huda, M.S., Drzal, L.T., Mohanty, A.K., Misra, M., 2008. Effect of fiber surfacetreatments on the properties of laminated biocomposites from poly(lactic acid) (PLA) and kenaf fibers. Compos. Sci. Technol. 68 (2), 424-432.

Islam, M.S., Pickering, K.L., Foreman, N.J., 2010. Influence of alkali treatment on the interfacial and physico-mechanical properties of industrial hemp fibre reinforced polylactic acid composites. Compos. A: Appl. Sci. Manuf. 41 (5), 596-603.

John, M.J., Thomas, S., 2008. Biofibres and biocomposites. Carbohydr. Polym. 71 (3), $343-364$.

Roya, K., 2008. Impact of the surface chemistry of rice hull ash on the properties of its composites with polypropylene. School of Civil and Chemical Engineering Science, Engineering and Technology Portfolio, RMIT University.

Lee, S.-H., Wang, S., 2006. Biodegradable polymers/bamboo fiber biocomposite with bio-based coupling agent. Compos. Part Appl. Sci. Manuf. 37 (1), 80-91.

Lu, J., Askeland, P., Drzal, L.T., 2008. Surface modification of microfibrillated cellulose for epoxy composite applications. Polymer 49 (5), 1285-1296.

Lung, C.Y.K., Matinlinna, J.P., 2012. Aspects of silane coupling agents and surface conditioning in dentistry: an overview. Dent. Mater. 28 (5), 467-477.

Meon, M.S., Othman, M.F., Husain, H., Remeli, M.F., Syawal, M.S.M., 2012. Improving tensile properties of kenaf fibers treated with sodium hydroxide. Procedia Eng. 41, 1587-1592.

Ndazi, B.S., Karlsson, S., Tesha, J.V., Nyahumwa, C.W., 2007. Chemical and physica modifications of rice husks for use as composite panels. Compos. A: Appl. Sci. Manuf. 38 (3), 925-935. 
Phuong, N.T., Sollogoub, C., Guinault, A., 2010. Relationship between fiber chemical treatment and properties of recycled pp/bamboo fiber composites. J. Reinf. Plast. Compos. 29 (21), 3244-3256.

Oh, S.Y., Yoo, D.I., Shin, Y., Kim, H.C., Kim, H.Y., Chung, Y.S., Park, W.H., Youk, J.H., 2005a. Crystalline structure analysis of cellulose treated with sodium hydroxide and carbon dioxide by means of X-ray diffraction and FTIR spectroscopy. Carbohydr. Res. 340 (15), 2376-2391.

Oh, S.Y., Yoo, D.I., Shin, Y., Seo, G., 2005b. FTIR analysis of cellulose treated with sodium hydroxide and carbon dioxide. Carbohydr. Res. 340 (3), 417-428.

Owens et, D.K., Wendt, R.C., 1969. Estimation of the surface free energy of polymers. J. Appl. Polym. Sci. 13 (8), 1741-1747.

Park, B.-D., Wi, S.G., Lee, K.H., Singh, A.P., Yoon, T.-H., Kim, Y.S., 2004. X-ray photoelectron spectroscopy of rice husk surface modified with maleated polypropylene and silane. Biomass Bioenergy 27 (4), 353-363.

Rahman, M.R., Huque, M.M., Islam, M.N., Hasan, M., 2009. Mechanical properties of polypropylene composites reinforced with chemically treated abaca. Compos. A: Appl. Sci. Manuf. 40 (4), 511-517.

Seki, Y., 2009. Innovative multifunctional siloxane treatment of jute fiber surface and its effect on the mechanical properties of jute/thermoset composites. Mater. Sci. Eng. A 508 (1-2), 247-252.

Sgriccia, N., Hawley, M.C., Misra, M., 2008. Characterization of natural fiber surfaces and natural fiber composites. Compos. A: Appl. Sci. Manuf. 39 (10), 1632-1637.
Shih, Y.-F., Huang, C.-C., Chen, P.-W., 2010. Biodegradable green composites reinforced by the fiber recycling from disposable chopsticks. Mater. Sci. Eng. A 527 (6), 1516-1521.

Sun, R., Lawther, J.M., Banks, W.B., 1995. Influence of alkaline pre-treatments on the cell wall components of wheat straw. Ind. Crops Prod. 4 (2), 127-145.

Threepopnatkul, P., Kaerkitcha, N., Athipongarporn, N., 2009. Effect of surface treatment on performance of pineapple leaf fiber-polycarbonate composites. Compos. B: Eng. 40 (7), 628-632.

Valadez-Gonzalez, A., Cervantes-Uc, J.M., Olayo, R., Herrera-Franco, P.J., 1999a. Effect of fiber surface treatment on the fiber-matrix bond strength of natural fiber reinforced composites. Compos. B: Eng. 30 (3), 309-320.

Valadez-Gonzalez, A., Cervantes-Uc, J.M., Olayo, R., Herrera-Franco, P.J., 1999b. Chemical modification of henequén fibers with an organosilane coupling agent. Compos. B: Eng. 30 (3), 321-331.

Yousif, B.F., Shalwan, A., Chin, C.W., Ming, K.C., 2012. Flexural properties of treated and untreated kenaf/epoxy composites. Mater. Des. 40, 378-385.

Yu, T., Ren, J., Li, S., Yuan, H., Li, Y., 2010. Effect of fiber surface-treatments on the properties of poly(lactic acid)/ramie composites. Compos. A: Appl. Sci. Manuf. 41 (4), 499-505.

Zafeiropoulos, N.E., Baillie, C.A., Hodgkinson, J.M., 2002. Engineering and characterisation of the interface in flax fibre/polypropylene composite materials. Part II. The effect of surface treatments on the interface. Compos. A: Appl. Sci. Manuf. 33 (9), 1185-1190. 